\title{
Exploring the Design Factors of Smart Glasses
}

\author{
Ali Emre Ok ${ }^{1}$, Nuri A Basoglu ${ }^{1}$, Tugrul Daim ${ }^{2}$ \\ ${ }^{1}$ Izmir Institute of Technology, Dept of Engineering Management, Urla, Izmir, Turkey \\ ${ }^{2}$ Dept. of Engineering and Technology Management, Portland State University. Portland, OR - USA
}

\begin{abstract}
Advances in information technology (IT) have started to focus studies on human computer interaction (HCI) which is an area in computer science embracing cognitive science. In this approach there are various aspects of researches about HCI in order to explore how people design, implement, and use interactive computer systems and how computers affect individuals, organizations, and society. This study represents exploring the adoption factors of smart glasses. Technology adoption process establishes preferences and needs of people who use computers and smart systems. To address this issue, technology adoption is essential for a rapidly changing world where technology has become central to our lives. In that context, user interface (UI) which provides interaction between user and computer, plays significant role for technology adoption process.

The purpose of the study is to examine the effects of smart glass design features; Stand-alone device, field of view, interaction, price, and display resolution on user preference through an experimental study by using conjoint analysis. In order to apply this study, an experimental study including a survey was designed. This survey also analyze social characteristics such as self-efficacy, anxiety, involvement, risktask characteristics, enjoyment, usefulness, ease of use, attitude and intention for user smart glasses interaction.
\end{abstract}

\section{INTRODUCTION}

Information technology (IT) is the field of computer and telecommunication in order to process data effectively. Smart devices which relate with the field of information technology (IT) become essential part of daily life in order to increase standards of living. Products and services which adapted developed technology provide people usefulness, efficiency and more discovered life. Human computer interaction (HCI) studies set light to simplify technology adoption process. People can use technology effectively with the contributions of HCI which is a research theory of evaluating IT systems.

This study aims to explore design factors on smart glasses and examine the users' potential decision on the use of smart glasses. Developing more usable systems is the objective of the HCI which studies the relationships between humans and computers. Companies and scientists make an effort innovative ways to use smart technology in order to enhance daily life of people. Smart technology gets new perspective for the fields of medical, education, entertainment, sports and commercial. It promotes these fields in order to develop more quality, easy and discovered life. Smart cars consume less fuel and take out less carbon emission, smart phones able facilitate life and connect people each other. Today smart glasses are ready to take significant role in order to enhance technology and provide users easy and useful ways to live. The success of smart glasses may encourage the continued research. Previous studies and technology adoption models made the most benefits for this study. Experimental study including a survey was conducted to analyze design factor of smart glasses. Participants contributed the study with their patience.

\section{LITERATURE REVIEW}

\section{A. Human Computer Interaction}

Human-computer interaction is a discipline concerned with the design, evaluation and implementation of interactive computing systems for human use and with the study of major phenomena surrounding them [1]. According to Pavlovic the existing HCI may be considered a bottleneck for the effective utilization of the available information flow with the development of computing, communication and display technologies [16].

HCI studies the relationships between humans and computers. HCI is not just defined with interfaces; it is more recent HCI research objectives are concerned with tasks, with shared understanding, and with explanations, justifications, and argumentation about actions. According to Fischer, the new essential challenges are improving the way people use computers to work, think, communicate, learn, critique, explain, argue, debate, observe, decide, calculate, simulate, and design.

People may use computer systems efficiently, effectively, safely and with satisfaction by the promotion of HCI which is a field of research theory, methodology and practice with the objective of designing, developing and evaluating computer based systems. HCI is cross-disciplinary field which contain human factors, ergonomics, cognitive psychology, behavioral psychology and psychometrics, systems engineering, and computer science [12].

\section{B. Usability}

Usability is the capacity of how user efficiently interacts with information systems with satisfaction for specific purposes. Developing more usable systems is the purpose of the human computer interaction issues. According to Chau and Hsiao, usability is the extent to which the user and the interface can communicate clearly, without misunderstanding through the interface [5].

Shackel defines usability of a system as "the capability in human functional terms to be used easily and effectively by the specified range of users, given specified training and user support, to fulfill the specified range of tasks within the specified range of environmental scenarios" [21]. 


\section{Technology Acceptance Model (TAM)}

Fred Davis proposed the technology acceptance model (TAM) which suggests user's motivation of technology can be influenced by perceived ease of use and perceived usefulness (Fig. 2.1) [8]. He hypothesized that the attitude of user is a main determinant to decide using of technology. Davis described perceived usefulness as "the degree to which a person believes that using a particular system would enhance his/her job performance" and perceived ease of use as "the degree to which a person believes that using a particular system would be free of effort". Technology Acceptance Model (TAM) provides effective solution that predicts adoption of new technologies [9].

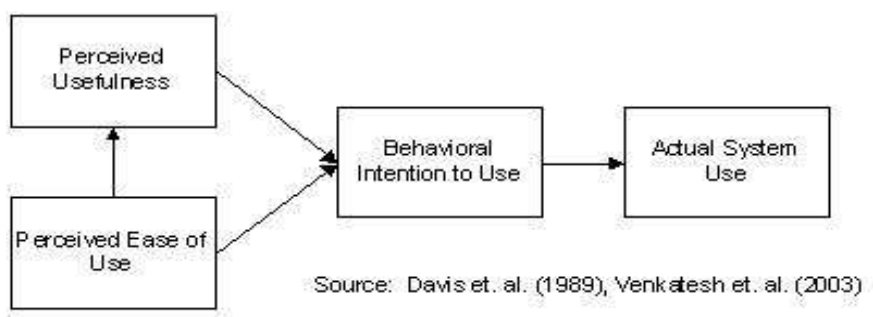

Fig. 2.1 Technology Acceptance Model

\section{Innovation}

Innovation described with new ideas on existing products, services, processes or other aspects of activities. Baregheh, Sambrook and Rowley mention innovation as, "Organizations need to innovate in response to changing customer demands and lifestyles and in order to capitalize on opportunities offered by technology and changing marketplaces, structures and dynamics" [2]. Innovation is frequently confused with invention which is the creation of the idea. Today companies don't need to invent something new to come to a head. Innovation presents significant opportunity to create market driven products and services.

\section{E. Conjoint Analysis}

According to Hermelbracht conjoint analysis is a wellestablished marketing research method which intends to examine customer preferences experimentally [13]. Conjoint analysis also examines the users' potential decisions on the use of products or services. It is generally used for new products and services which have yet to be developed. Conjoint Analysis gives a picture of the future shape of services. It is widely used in commercial applications, fields of pricing policy and development of new products. Conjoint Analysis concerns on "attributes" and "levels". Products or services are "attributes", and their different preferences represent the "levels". Combining levels of different attributes allows researchers to provide conjoint analysis [13].

Through the conjoint analysis researchers can determine the relative importance of each attribute and levels of each attribute are most preferred. If the most preferable product is not feasible for some reason, such as cost, the next most preferred alternative can be discovered. Researchers can collect other information data on the respondents such as demographics. They might be able to identify market segments for which distinct products can be chosen. For instance, the business traveler and the student traveler might have different preferences that could be met by distinct product offerings (IBM).

\section{F. Smart Glasses}

Smart glasses are wearable smart devices that enable to bring computing data and internet access into users' field of view through heads up display (HUD) which is an optics technology. Smart glass users can see the display independently of user's position. They provide users with technological and information possibilities. Smart glasses allow users to make activities such as connecting internet, sending messages, taking photos\& videos, searching locations and running mobile apps.

Companies continue to work on virtual reality and augmented reality in order to alter visual information. Virtual reality smart glasses can allow users to create completely virtual world in order to experience unreal display. Augmented reality smart glasses perceive users real world with virtual content that is created by computing systems [18]. Usage areas of smart glasses are medical, education, entertainment, sports and commerce. Voice warning and navigation for blind people, subtitles for deaf peoples and physical therapies through virtual reality for patients are point of medical field related with smart glasses. Simulations for education field, 3D cinemas and games for education field and performance measurement for sports field might change technologic perception through smart glasses. Smart glasses contain camera, compass, calculator, thermometer, accelerometer, speaker and navigation.

\section{METHODOLOGY}

The intention of survey study was to collect data from participants to use for conjoint analysis. Approximately 130 participants joined to the survey study. However responses of 80 participants were accepted for conjoint analysis because of lack of responses on specific part of question. First part guided participants to explore the purpose of the experimental study. The second part includes videos related with smart glasses. The third part contains demographic questions to collect age, gender and education responses. The forth part includes social intention characteristics questions about smart glasses. The final part contains the main conjoint analysis question.

The experimental study was executed on the Internet via a SurveyMonkey which is an online survey development cloud based software service company. SurveyMonkey provides data collection, data analysis, brand management, and consumer marketing. Participants were informed by Facebook and e-mail including web site's link for experimental study. A web site's link was shared with friends via Facebook in order to reach various people. E-mail 
including web site link was also sent to friends, university students and academicians. People were also shared with their friends. Survey was applied through the SurveyMonkey web site.

The survey contains five parts. First part is the information page which manipulates participants to understand experimental study more comprehensive. The second part includes three videos related with smart glasses in order to present and make interaction smart glasses with participants. The third page consists of demographic questions to take age, gender and education level information. The fourth page is survey questions related with social intention characteristics such as self-efficacy, anxiety, involvement, risk- task characteristics, enjoyment, usefulness, ease of use, attitude and intention for user smart glasses interaction. This page was examined to test user intention framework which contains the extent of agreement and disagreement with various statements on a four-point likert scale ranging from (1) disagree to (4) agree. The final page includes conjoint analysis part of the experimental study. There are also informative pictures and instructions on that page in order to understand process clearly.

Traditional full-profile conjoint analysis is used for this study and it is the most fundamental approach for measuring attribute utilities. According to full-profile conjoint analysis, various product descriptions are developed and presented to the participants for preference evaluations. Attributes and levels of the product were specified in order to measure utility. Attribute is the feature of the product and level is the values of each attributes. Alternative is the set of attributes and its levels. All attributes that characterize the alternatives were considered. If some alternatives were not feasible to subjects, these profiles kept out for the experimental study. Participants ranked alternatives according to their agreements or disagreements.

Identifying attributes should be supported by potential range of preferences and values that people may hold. What may be important to the respondent and what is relevant to the particular product were determined in order to identify attributes. In that context, stand- alone device, field of view, interaction, price and display resolution are five attributes of the design factors of the smart glasses for this study.

SPSS (Statistical Package for the Social Sciences) Statistics 22 was used for the conjoint analysis. Firstly attributes and levels data of smart glasses were entered to the system. In that context there were 48 alternatives for five attributes and its level. However there are some alternatives which were not feasible to subjects. These alternatives kept out the conjoint analysis. Finally SPSS conjoint formed with 8 alternatives to enable participants to rank (Table 3.1).

The attribute of standalone device has two levels; "Yes" and "No". Field of view attribute has " 12 " " and " $65^{\circ}$ " levels. Interaction has two levels; "Voice recognition\& Touchpad" and "Hand gestures". Price includes three levels; "300\$", "600\$" and "1000\$". Finally Display resolution attribute has "1024x768" and "640x360" levels.

For example Alternative 1 represents non standalone device, $12^{\circ}$ field of view, interaction with voice recognition\& touchpad, $300 \$$ price and $1024 \times 768$ pixel display resolution. It means that smart glass is required to external device in order to use operating system and processor. It has low field of view and use voice command\& touching techniques to interaction. Price of that smart glass is $300 \$$ and it has high definition (HD) display resolution. The screen of the survey where the alternatives were presented can be seen in Fig. 3.1.

Participants ranked these alternatives with respect to their assessments about smart glasses from the most (1) to the least (8) desirable. Part- worth utilities (PWU) of attributes is the one of the conjoint analysis output that provide to determine what product design characteristics and what levels of product design characteristics are the most and least desirable for the user. This output of the conjoint analysis was used to find out the market shares of the most preferred products. The output results were used in SPSS conjoint analysis in order to analyze design factors of smart glasses.

TABLE 3.1 SPSS CONJOINT ALTERNATIVES

\begin{tabular}{|c|c|c|c|c|c|}
\hline Alternative & Standalone device & Field of view & Interaction & Price & $\begin{array}{l}\text { Display } \\
\text { Resolution }\end{array}$ \\
\hline 1 & No & $12^{\circ}$ & $\begin{array}{l}\text { Voice recognition \& } \\
\text { Touchpad }\end{array}$ & $300 \$$ & $1024 \times 768$ \\
\hline 2 & Yes & $65^{\circ}$ & $\begin{array}{l}\text { Voice recognition \& } \\
\text { Touchpad }\end{array}$ & $600 \$$ & $640 \times 360$ \\
\hline 3 & Yes & $12^{\circ}$ & Hand gestures & $600 \$$ & $1024 \times 768$ \\
\hline 4 & No & $65^{\circ}$ & $\begin{array}{l}\text { Voice recognition \& } \\
\text { Touchpad }\end{array}$ & $600 \$$ & $1024 \times 768$ \\
\hline 5 & No & $65^{\circ}$ & Hand gestures & $600 \$$ & $1024 \times 768$ \\
\hline 6 & Yes & $12^{\circ}$ & $\begin{array}{l}\text { Voice recognition \& } \\
\text { Touchpad }\end{array}$ & $600 \$$ & $1024 \times 768$ \\
\hline 7 & Yes & $65^{\circ}$ & Hand gestures & $1000 \$$ & $1024 \times 768$ \\
\hline 8 & No & $12^{\circ}$ & Hand gestures & $300 \$$ & $640 \times 360$ \\
\hline
\end{tabular}


2015 Proceedings of PICMET '15: Management of the Technology Age

\begin{tabular}{|c|c|c|c|c|}
\hline$\nabla$ & & & & \\
\hline Bağımsız Cihaz & Görüntü Alanı & Etkileşim & Fiyat & t Görüntü Kalitesi \\
\hline Hayır & $12^{\circ}$ & Ses ve Dokunarak & $300 \$$ & $1024 \times 768$ \\
\hline \multicolumn{5}{|l|}{$\checkmark$} \\
\hline Bağımsız Cihaz & Görüntü Alanı & Etkileşim & Fiyat & t Görüntü Kalitesi \\
\hline Evet & $65^{\circ}$ & Ses ve Dokunarak & $600 \$$ & $640 \times 360$ \\
\hline \multicolumn{5}{|l|}{ 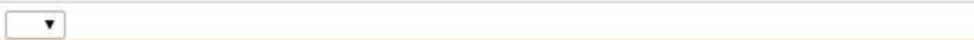 } \\
\hline Bağımsız Cihaz & Görüntü Alanı & Etkileşim & Fiyat & Görüntü Kalitesi \\
\hline Evet & $12^{\circ}$ & El komutu & $600 \$$ & $1024 \times 768$ \\
\hline \multicolumn{5}{|l|}{ V } \\
\hline Bağımsız Cihaz & Görüntü Alanı & Etkileşim & Fiyat & t Görüntü Kalitesi \\
\hline Hayır & $65^{\circ}$ & Ses ve Dokunarak & $600 \$$ & $1024 \times 768$ \\
\hline \multicolumn{5}{|l|}{ 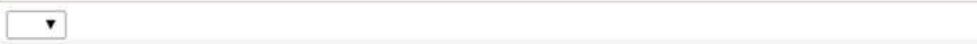 } \\
\hline Bağımsız Cihaz & Görüntü Alanı & Etkileşim & Fiyat & Görüntü Kalitesi \\
\hline Hayır & $65^{\circ}$ & El komutu & $600 \$$ & $1024 \times 768$ \\
\hline \multicolumn{5}{|l|}{$\nabla$} \\
\hline Bağımsız Cihaz & Görüntü Alanı & Etkileşim & Fiyat & Görüntü Kalitesi \\
\hline Evet & $12^{\circ}$ & Ses ve Dokunarak & $600 \$$ & $1024 \times 768$ \\
\hline \multicolumn{5}{|l|}{$\nabla$} \\
\hline Bağımsız Cihaz & Görüntü Alanı & Etkileşim & Fiyat & Görüntü Kalitesi \\
\hline Evet & $65^{\circ}$ & El komutu & $1000 \$$ & $1024 \times 768$ \\
\hline \multicolumn{5}{|l|}{ 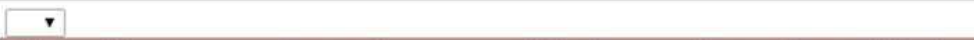 } \\
\hline Bağımsız Cihaz & Görüntü Alanı & Etkileşim & Fiyat & Görüntü Kalitesi \\
\hline Hayır & $12^{\circ}$ & El komutu & $300 \$$ & $640 \times 360$ \\
\hline
\end{tabular}

Fig. 3.1 Experimental fifth page screen

\section{RESULTS}

The product design characteristics of smart glass consist of five variables; standalone device, field of view, interaction, price and display resolution.

Standalone smart glass models have own mobile operating system such as Android. They have also own processor, RAM and internal storage. There are some smart glasses which don't locate own hardware and software. Nonstandalone devices connect to other devices like mobile phones through USB port. These devices use operating system of mobile phones or tablet in order to compute system and bring computing display. In this approach standalone variable has influence on design factor of smart glasses because of being independent device. On the other hand nonstandalone device has advantages of production cost and weight of product. This device can plug into select Android phones to leverage their processing power.

Various smart glasses are ready to be launched and already be launched with different field of view (FOV) features. FOV represents to the angle of viewers perspective of display. Humans have capability of 180 degree horizontal field of view. Large field of view increases the satisfaction level of viewers who concern on any activities. Companies work to enhance field of view preference in order to gain competitive advantage. FOV of the smart glass models vary between 12 degrees to 65 degrees.
Interaction represents commands of the smart glasses. According to Bertarini there are two different interaction methods can be distinguished for smart glasses; free form and others [4]. The former contains eye tracking, wink detection, voice commands, and gestures performed with fingers or hands. On the other hand, the others include the use of handheld devices, such as smart phones, keyboards, point-andclick controllers, joysticks, or smart watches. Free form devices don't need any extra device to perform or control but others are controlled by pointers. In that context gesturebased interaction smart glasses are more ideal devices than others which need external pointers, keyboard or smart phones. Voice recognition based devices was already launched for mobile devices. It is also applied into smart glasses with to be ease of use and usefulness. Touchpad technology can be generally located into the devices because it requires more time to enhance gesture technologies. Our findings will give direction to interaction influences on design factor of smart glasses.

Price is the determinant factor for potential user decides to purchase products and services. In field of smart glasses there are also ultimate price competitions. Companies strive to decrease production costs of smart glasses in order to provide appropriate price of product. Customers should have enough power to purchase or prefer one of the smart glasses. As studies indicate, price influences on design factor of smart glasses. 
Resolution represents to how many pixels the display has and how these pixels are packed. The higher resolution has better display quality and it is more satisfactory for the viewer. Display resolution of smart glasses varies between resolution of $320 \times 240$ and resolution of $1920 \times 1080$ (HD). Display resolution influences on design factor of smart glasses.

\section{A. The profile of the participants}

The profile of the participants who joined survey study can be seen in Table 4.1.

\begin{tabular}{lll}
\multicolumn{2}{c}{ TABLE 4.1 THE PROFILE OF THE PARTICIPANTS } \\
\hline Variable & Percentage & Frequency \\
\hline Gender & & \\
Male & $49.2 \%$ & 63 \\
Female & $50.8 \%$ & 65 \\
Age & & \\
24 and lower & $25.8 \%$ & 33 \\
$25-29$ & $60.9 \%$ & 78 \\
$30-34$ & $7.8 \%$ & 10 \\
$35-39$ & $2.3 \%$ & 3 \\
$40-44$ & $1.6 \%$ & 2 \\
45 and higher & $1.6 \%$ & 2 \\
Education & & \\
High school graduate & $4.6 \%$ & 6 \\
University student & $18.8 \%$ & 24 \\
University graduate & $76.6 \%$ & 98 \\
\hline
\end{tabular}

The results show that the sample mostly aged between twenty-five and twenty- nine. 65 participants are female and 63 participants are male. There is an affinity according to gender comparison. Participants are frequently university graduate with 76 percentage of attendance.

\section{B. Findings of exploring design factors of smart glasses}

Conjoint analysis of SPSS was used to explore design factors of smart glasses with the collecting data from the survey. Through the conjoint analysis the relative importance of each attribute and levels of each preferred attribute are explored. The output of conjoint analysis, which shows the importance of attributes and its associated levels, is shown below (Table 4.2).

\begin{tabular}{llcl}
\multicolumn{4}{c}{ TABLE 4.2 PRODUCT UTILITY TABLE } \\
\hline & & $\begin{array}{c}\text { Utility } \\
\text { Estimate }\end{array}$ & Std. Error \\
\hline Standalone device & Yes & 1.735 & 0.349 \\
& No & -1.735 & 0.349 \\
Interaction & Hand gesture & 0.227 & 0.145 \\
& Voice rec. \& Touchpad & -0.227 & 0.145 \\
Price & $300 \$$ & 2.000 & 0.888 \\
& $600 \$$ & -0.035 & 0.168 \\
Display resolution & $1000 \$$ & -1.965 & 0.839 \\
\multirow{4}{*}{ Field of view } & $640 \times 360$ & -0.919 & 0.252 \\
& $1024 \times 768$ & 0.919 & 0.252 \\
(Constant) & 12 & -1.346 & 0.349 \\
\hline
\end{tabular}

According to conjoint analysis when we look at utility table, $300 \$$ smart glass price has highest utility value which is 2.000 . Therefore price attribute with $300 \$$ level is the most important and desired value among the other values. The second important value is standalone device attribute which is 1,735. The third highest utility value is field of view with 65 degree. High display resolution and hand gesture interaction followed these values. Besides $1000 \$$ smart glass price is the least desirable value which is -1.965 . Non standalone devices, field of view with 12 degree and low display resolutions are dissatisfactory values as shown in Table 4.2.

Table 4.3 shows the averaged importance score of values that influence the user preference. The most important factor which influenced participant's preference is price with 32 percentages. The second averaged important score is standalone device $(28 \%)$ which is approximate to price value. Field of view is the third important value with 22 percentages. Display resolution has 15 percentage of importance value among other values. The lowest importance score is interaction value (4\%).

\begin{tabular}{lc} 
TABLE 4.3 AVERAGED IMPORTANCE SCORE \\
\hline Importance Values \\
\hline Standalone device & $28 \%$ \\
Interaction & $4 \%$ \\
Price & $32 \%$ \\
Display resolution & $15 \%$ \\
Field of view & $22 \%$ \\
\hline
\end{tabular}

Conjoint analysis results show that the participants desired to use low price smart glass. Price is the determinant factor for potential user decides to purchase smart glasses. This study shows that low price has positive influence on design factor of smart glasses. Standalone device is the second important and desired smart glass preference according to participants. In that context standalone variable has positive influence on participants because of locating own software and hardware inside the device. Potential smart glass users also intended to use smart glasses that have large field of view which increases the satisfaction level of participants and it has positive influence on design factor of smart glasses. It is surprisingly shown that interaction has the lowest level importance according to participants. Moreover hand gesture is more desired interaction than voice recognition\& Touchpad. As studies indicate gesture- based interaction smart glasses are more preferable devices than others which need external devices such as keyboard and pointers. The least desirable smart glass attribute is high price product which has negative influence on participants.

Part- worth utilities (PWU) of alternative smart glasses which provide to determine what product design characteristics and what levels of product design characteristics are the most and least desirable for the user, is shown in Table 4.4. 
2015 Proceedings of PICMET '15: Management of the Technology Age

\begin{tabular}{|c|c|c|c|c|c|c|}
\hline Rank & Alternative & $\begin{array}{l}\text { Standalone } \\
\text { device }\end{array}$ & Field of view & Interaction & Price & $\begin{array}{l}\text { Display } \\
\text { Resolution }\end{array}$ \\
\hline 1 & 2 & Yes & $65^{\circ}$ & $\begin{array}{l}\text { Voice recognition \& } \\
\text { Touchpad }\end{array}$ & $600 \$$ & $640 \times 360$ \\
\hline 2 & 3 & Yes & $12^{\circ}$ & Hand gestures & $600 \$$ & $1024 \times 768$ \\
\hline 3 & 7 & Yes & $65^{\circ}$ & Hand gestures & $1000 \$$ & $1024 \times 768$ \\
\hline 4 & 4 & No & $65^{\circ}$ & $\begin{array}{l}\text { Voice recognition \& } \\
\text { Touchpad }\end{array}$ & $600 \$$ & $1024 \times 768$ \\
\hline 5 & 5 & No & $65^{\circ}$ & Hand gestures & $600 \$$ & $1024 \times 768$ \\
\hline 6 & 1 & No & $12^{\circ}$ & $\begin{array}{l}\text { Voice recognition \& } \\
\text { Touchpad }\end{array}$ & $300 \$$ & $1024 \times 768$ \\
\hline 7 & 6 & Yes & $12^{\circ}$ & $\begin{array}{l}\text { Voice recognition \& } \\
\text { Touchpad }\end{array}$ & $600 \$$ & $1024 \times 768$ \\
\hline 8 & 8 & No & $12^{\circ}$ & Hand gestures & $300 \$$ & $640 \times 360$ \\
\hline
\end{tabular}

Table 4.4 shows that participants mostly desired to use alternative number 2 which is standalone device, large field of view, voice recognition\& touchpad interaction, medium price and 640x360 display resolution. Participants preferred to use the 8th alternative to the least which is non-standalone device, small field of view, hand gesture interaction, low price and 640x360 display resolution. Non standalone device, small field of view and medium display resolution have negative influence on smart glasses design.

\section{Findings of User Intention characteristics}

Survey data related with social characteristics such as self-efficacy, anxiety, involvement, risk- task characteristics, enjoyment, usefulness, ease of use, attitude and intention were collected in order to analyze effects on design of smart glasses. Participants ranged each of characteristics according to their agreement and disagreement degrees with various statements on a four-point likert scale ranging from (1) disagree to (4) agree. The results are shown in Table 4.5.

In this study the mean value of enjoyment is the highest point with 3.3. It is shown in Table 4.5 that participants agree to enjoy using smart glasses. Participants also decided to have self-efficacy to use smart glasses. They are primarily influenced by their friends, family and neighborhood in order to prefer one of the smart glasses. Then participants are influenced by news, advertisements and other external things. They partially agree that using smart glass is a risky task. Their attitude to prefer using smart glass is positive. Participants agree that it is easy to use and usefulness. They have little bit anxiety and health concern on using smart glass. It is also seen that they are not exactly ready to intend using smart glass. In that context companies may delay or anticipate right time to present their products. Finally participants are found using smart glasses complex on an average.

\section{DISCUSSION}

As this study indicates price is the predominant factor that shows the effect on smart glass design. Participants agreed to prefer low price product when they have chosen one of the smart glasses. There are ultimate price competitions on the market. These companies have research and development departments in order to decline production costs for increasing sales volume. As this study indicates, low price has positive influence on design factor of smart glasses. In contrast high price has negative influence as shown at the conjoint analysis. The important of price policy applies to other products and services that people need, want and prefer.

The second important characteristic is standalone device which influence adoption of smart glasses. These devices can be independent with using own hardware and software. Participants preferred to use standalone device according to the conjoint analysis. There are many information technology based companies compete each other to differentiate themselves. The power of the hardware and software systems can be determinant factor to design smart glasses. Today

TABLE 4.5 STATISTICS FOR USER INTENTION CHARACTERISTICS

\begin{tabular}{|c|c|c|c|c|c|c|c|}
\hline & Mean & $\begin{array}{l}\text { Standard } \\
\text { deviation }\end{array}$ & Median & Mode & Min & Max & $\mathrm{N}$ \\
\hline Enjoyment & 3.311 & 0.796 & 3 & 4 & 1 & 4 & 121 \\
\hline Self-Efficacy & 3.131 & 0.782 & 3 & 3 & 1 & 4 & 121 \\
\hline Peer Influence & 3.008 & 0.766 & 3 & 3 & 1 & 4 & 121 \\
\hline External influence & 2.922 & 0.713 & 3 & 3 & 1 & 4 & 121 \\
\hline Risk & 2.677 & 0.968 & 3 & 3 & 1 & 4 & 121 \\
\hline Attitude & 2.644 & 0.424 & 2.7 & 2.7 & 1 & 4 & 121 \\
\hline Usefulness & 2.628 & 0.722 & 2.7 & 2.7 & 1 & 4 & 121 \\
\hline Ease of use & 2.426 & 0.362 & 2.5 & 2.5 & 1 & 4 & 121 \\
\hline Anxiety & 2.098 & 0.797 & 2 & 2 & 1 & 4 & 121 \\
\hline Health Concern & 2.032 & 0.953 & 2 & 2 & 1 & 4 & 121 \\
\hline Intention & 1.901 & 0.837 & 2 & 2 & 1 & 4 & 121 \\
\hline Complexity & 1.803 & 0.664 & 2 & 2 & 1 & 4 & 121 \\
\hline
\end{tabular}




\section{Proceedings of PICMET '15: Management of the Technology Age}

Android is unrivalled operating system for mobile devices with the power of multitasking and easy access to thousands of application. Companies take the advantages of Android and build their technologies on its power. Smart glasses companies also gain leverage of Android. Furthermore, nonstandalone devices need other devices such as mobile phones but production cost and weight of product are the advantages of it. In this study participants didn't intend to use nonstandalone smart glasses.

Corresponding to study results, Field of view is the third important characteristic. Utility values show that participants intended to use large field of view. Restricting field of view affects potential smart glass users. Alternative smart glasses which have 65 degree field of view are in the top five alternatives according to product ranks table. Companies maintain to develop field of view technology in order to satisfy their customer. However some potential users can intend to use small field of view because it increases multitasking. When people use their smart glasses, they want to drive, walk or make activities. Therefore using large field of view may not have advantage every time.

Display resolution of smart glasses is seen satisfactory. Companies generally give preference smart glasses to $1920 \mathrm{x}$ 1080 high definition display resolution. However low display quality influence users negatively and they don't intend to use it.

Interaction has the lowest utility level for the participants. In this study there are two type of interaction; Hand gesture and voice recognition with touchpad. Hand gestures interaction contains virtual augmented reality and it is open to improvement at this technologic circumstances. Voice recognition already adapted for the mobile devices. It is also useful and easy to use for potential buyers. In this study participants preferred to use hand gestures interaction more than voice recognition.

Corresponding to findings of user intention characteristics, enjoyment, self-efficacy, peer influence, external influences are high agreements of participants in order to use smart glass. They also considered that using smart glasses is moderately risky. Product ease of use and usefulness should be significant by designers to satisfy users. In that context participants had positive attitude to use smart glasses and they found useful these devices. Designers should take care to these characteristics for product design achievement. In addition, ease of use towards using smart glass affected participants positively.

\section{CONCLUSION}

This study aims to explore and understand the design factors of smart glass through qualitative and quantitative techniques with the intention of achieving product utility, usability, and ease of use. Technology adoption process was applied which was developed through survey study. Conjoint analysis ensured ultimate contributions to develop this study.
It provided to examine the participants' potential decision on the use of smart glasses.

In this study price is the most important factor that influence on smart glass design. In contrast interaction is the least important attribute that affects user preferences. Standalone device, field of view and display resolution moderately influence smart glass design. The results may be changed according to demographic distribution. For example participants are generally aged between twenty-five and twenty- nine. They are mostly university graduates for this study. There are five different attributes to analyze smart glass design study. Each of values has different impacts on smart glass adoption. If attributes number was decreased or values were analyzed independently, the importance values could be shifted.

Corresponding to intention characteristics participants really enjoyed to interact with smart glasses. They have high self-efficacy towards the issue of using smart glass. Peer and external influences are important characteristics of participants. Smart glasses were also accepted positive attitudes, useful and easy to use.

Traditional conjoint analysis has a limited ability to study many attributes. Therefore there are 5 attributes to analyze design factors on smart glasses. In this approach most appropriate attributes (Standalone device, field of view, price, interaction, and display resolution) were tried to assign for this study. Survey study was satisfactory and efficient in order to make conjoint analysis and intention characteristics framework. The results offered an insight into exploring design factor on smart glasses.

\section{REFERENCES}

[1] ACM Specialist Interest Group on Computer Human Interaction Curriculum Development Group; Technical report. ACM, New York, (1992).

[2] Baregheh, A., Rowley, J., and Sambrook, S.; Towards a multidisciplinary definition of innovation. Management decision, 47(8),1323-1339. (2009).

[3] Basoglu, N., Daim, T.U., and Topacan, U.; Determining Patient Preferences for Remote Monitoring. Journal of Medical Systems, 36(3),1389-1401. (2011).

[4] Bertarini, M.; Smart glasses: Interaction, privacy and social implications. Ubiquitous Computing Seminar FS2014 Student report. (2014).

[5] Chou, J. and Hsiao, S.; A usability study on human-computer interface for middle-aged learners. Computers in Human Behavior, 23 (4), 20402063. (2007).

[6] Chou, P. Y. K. and Hu, J. H.; Investigating healthcare professionals' decisions to accept telemedicine technology: An empirical test of competing theories. Information \& Management, 39 (4), 277-287 (2002).

[7] Chuttur, M.Y.; Overview of the Technology Acceptance Model: Origins, Developments and Future Directions. Indiana University, USA . Sprouts: Working Papers on Information Systems, 9(37). Indiana University, USA. Retrieved from http://sprouts.aisnet.org/785/1/TAMReview.pdf on 25 August. (2010).

[8] Davis, F. D.; Perceived Usefulness, Perceived Ease of Use and User Acceptance of Information Technology. MIS Quarterly, 13. (1989).

[9] Due, B. L.; The future of smart glasses: An essay about challenges and possibilities with smart glasses. Working papers on interaction and 


\section{Proceedings of PICMET '15: Management of the Technology Age}

communication, 1(2), 1-21, 2014. Centre of Interaction Research and Communication Design, University of Copenhagen (2014).

[10] Fetaji, M., Loskoska S., Fetaji B., and Ebibi M.; Investigation Human Computer Interaction Issues in Designing Efficient Virtual Learning Environments. Balkan Conference in Informatics (BCI 2007), 2007, Bulgaria. pp.313-324. (2007).

[11] Fischer, G.; User Modeling in Human Computer Interaction. User Modeling and User-Adapted Interaction 11, 65-86.(2001).

[12] Hartson, H. R.; Human-computer interaction: Interdisciplinary roots and trends. The Journal of Systems and Software, 43(2), 103-118. (1998).

[13] Hermelbracht, A. and Koeper, B.; Development of new library services by means of Conjoint Analysis. Library Hi Tech 24, 595-603. (2006).

[14] IBM Corporation; IBM SPSS Conjoint 20 Manual. (2011).

[15] Kargun, B., Basoglu, N., and Daim, T.; Adoption Factors of Mobile Services. International Journal of Information Systems in the Service Sector, 1(1),15-34,Jan-Mar. (2009)

[16] Pavlovic, V. I., Sharma R., Huang T.S.; Visual Interpretation of Hand Gestures for Human-Computer Interaction. (1997).
[17] Polat, E., Basoglu, N., and Daim, T.; Effects of Adaptivity and Other External Variables on Mobile Service Adaption. International Journal of Information Systems in the Service Sector, 3(3),71-89. (2011).

[18] Schweizer, H.; Smart glasses: Technology and applications. Student report. (2014)

[19] Seneler, C.O., Basoglu, N., and Daim, T.; Interface feature prioritization for web services: Case of online flight reservations. Computers in Human Behavior, 25(4),826-877. (2009).

[20] Seneler, C.O. and Basoglu, N.; Exploring the Contribution of the Design Characteristics of Information Systems' User Interface to the Adoption Process. Int. J. of Business Information Systems, 4(5), 489 508. (2009).

[21] Shackel, D.; Usability: Context, Framework, Definition, Design and Evaluation, in Human Factors for Informatics Usability. Cambridge University Press. (1991).

[22] Visser, P. S., Krosnick, J.A., and Lavrakas, P. J.; Survey Research. (2000). 